\title{
ChemComm
}

Cite this: Chem. Commun., 2013, 49, 4355

Received 1st October 2012, Accepted 1st November 2012

DOI: $10.1039 / \mathrm{c} 2 \mathrm{cc} 37148 \mathrm{k}$

www.rsc.org/chemcomm

\section{Vibrational spectroscopic observation of ice dewetting on $\mathrm{MgO}(001) \dagger \ddagger$}

\author{
Esther Carrasco, Andreas Aumer, Janaina F. Gomes, Yuichi Fujimori and \\ Martin Sterrer*
}

The properties of the interfacial water monolayer on $\mathrm{MgO}(001)$ during growth of multilayer ice and, in particular, the dewetting of crystalline ice on $\mathrm{MgO}(001)$ are revealed by vibrational sum frequency generation and infrared reflection absorption spectroscopy.

The interaction of water with surfaces is of fundamental interest due to its importance in a wide range of environmental and technological processes. Of the many facets summarized in a number of review papers, ${ }^{1}$ the wetting behavior of water on metal surfaces, and its effects on the subsequent growth of crystalline ice (CI) multilayers, has recently gained renewed interest. ${ }^{2}$ The most recent studies of such phenomena have been summarized by Hodgson and Haq for a variety of low Miller-index, transition-metal surfaces. ${ }^{3}$ From that work, it seems that hydrogen bonding between interfacial and subsequent water layers plays a pivotal role in determining the wetting behavior of multilayer ice upon crystallization. As such, those systems allowing for greater rearrangement of the interfacial monolayer tend to better stabilize the CI-metal interface and vice versa. ${ }^{3}$

While most of the recent findings dealing with ice dewetting have been obtained via diffraction, rare gas adsorption, and scanning tunneling microscopy, ${ }^{3}$ vibrational spectroscopy is often the method of choice for studies of adsorbed water, as it simultaneously provides information about the interactions of molecules within the submonolayer (water bonding/types of H-bonds) and the multilayer (amorphous or crystalline) regime. ${ }^{4}$ However, since thick ice layers tend to mask monolayer signals with strong absorption of their own, and wetted monolayers do not show distinct vibrational features over many of the transition-metal surfaces, IR has been largely neglected for this application.

In this work, this topic is extended to non-metal surfaces by studying the wetting behavior of monolayer and multilayer water on a single-crystalline $\mathrm{MgO}(001)$ surface, for which the state of the monolayer can be followed using sum frequency generation (SFG) and infrared reflection absorption spectroscopy (IRAS), even when

Department of Chemical Physics, Fritz-Haber-Institut der Max-Planck-Gesellschaft, Faradayweg 4-6, 14195 Berlin, Germany. E-mail: sterrer@fhi-berlin.mpg.de

$\dagger$ This article is part of the ChemComm 'Emerging Investigators 2013' themed issue. ‡ Electronic supplementary information (ESI) available: Experimental details. See DOI: $10.1039 / \mathrm{c} 2 \mathrm{cc} 37148 \mathrm{k}$ a) $\mathrm{p}(3 \times 2) / 6 \mathrm{H}_{2} \mathrm{O}$
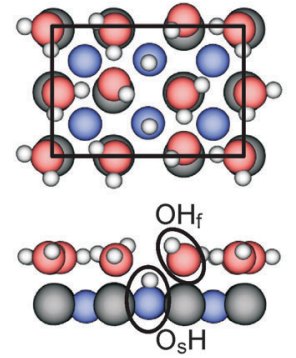

b) $\mathrm{c}(4 \times 2) / 10 \mathrm{H}_{2} \mathrm{O}$
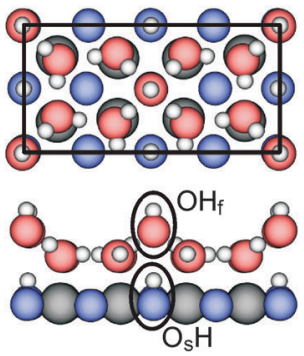

Fig. 1 The two most stable ordered water monolayer structures on $\mathrm{MgO}(001)$. (a) $\mathrm{p}(3 \times 2) / 6 \mathrm{H}_{2} \mathrm{O}$ and (b) $\mathrm{c}(4 \times 2) / 10 \mathrm{H}_{2} \mathrm{O}^{5 h}$

buried under a thick layer of ice. Together, the results provide the first spectroscopic observation of ice dewetting during transition from amorphous solid water (ASW) to CI.

Laterally ordered layers of water on single-crystalline oxide surfaces are rare. For bulk terminated oxides, compelling evidence of an ordered water monolayer exists only for $\mathrm{MgO}(001)$, where $\mathrm{c}(4 \times 2)$ and $\mathrm{p}(3 \times 2)$ overlayers, Fig. 1 , with mixed molecular/dissociated water adsorption structures were found to be stable between $100 \mathrm{~K}$ and $200 \mathrm{~K} .{ }^{5}$ The dissociated water molecules yield two different types of hydroxyl species within both structures: the free $\mathrm{OH}$ group designated as $\mathrm{OH}_{\mathrm{f}}$, which sticks out of the monolayer into vacuum, and the surface $\mathrm{OH}$ group designated as $\mathrm{O}_{\mathrm{s}} \mathrm{H}$, which is created by transfer of the proton remaining after water dissociation to an oxygen anion in the surface layer. The $\mathrm{OH}_{\mathrm{f}}$ groups give rise to a single vibrational feature at 3685 $\mathrm{cm}^{-1}(\mathrm{OH}) / 2722 \mathrm{~cm}^{-1}(\mathrm{OD})$. By contrast, the $\mathrm{O}_{\mathrm{s}} \mathrm{H}$ groups exhibit slightly different vibrational frequencies in the two overlayers, $3570 \mathrm{~cm}^{-1}(\mathrm{OH}) / 2639 \mathrm{~cm}^{-1}(\mathrm{OD})$ for $\mathrm{c}(4 \times 2)$, and $3515 \mathrm{~cm}^{-1}(\mathrm{OH}) /$ $2593 \mathrm{~cm}^{-1}(\mathrm{OD})$ for $\mathrm{p}(3 \times 2)$, respectively, and provide a sensitive probe for the presence of the respective structures. ${ }^{5 h}$

To probe the fate of the interfacial water- $\mathrm{MgO}$ monolayer below ice layers of varying thickness SFG has been applied because of its interface sensitivity. Fig. 2a shows a series of SFG spectra of $\mathrm{MgO}(001)$ obtained after increasing (from bottom to top) $\mathrm{H}_{2} \mathrm{O}$ dose at $90 \mathrm{~K}$. At the initial stage of ice growth $\left(0.5 \mathrm{~L}\right.$ dose, $1 \mathrm{~L}=1 \times 10^{-6}$ torr s) the spectrum contains two narrow resonances at 3515 and 

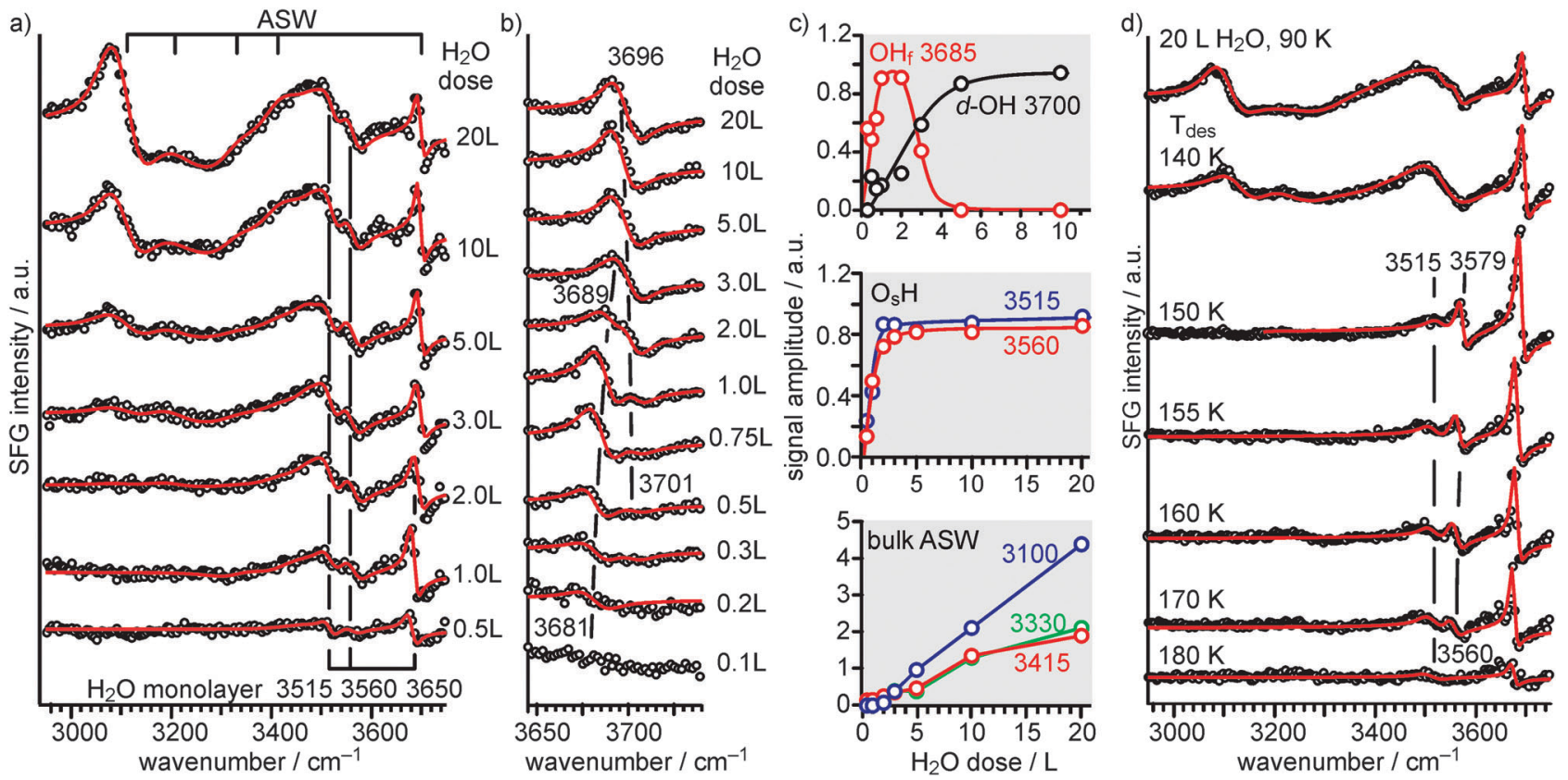

Fig. 2 (a) Series of SFG spectra for increasing dose (from bottom to top) of $\mathrm{H}_{2} \mathrm{O}$ adsorbed on the $\mathrm{MgO}(001)$ surface at $90 \mathrm{~K}$. (b) Details of the spectral region around $3700 \mathrm{~cm}^{-1}$. (c) Plots of SFG amplitude vs. $\mathrm{H}_{2} \mathrm{O}$ dose for selected vibrational bands obtained from fits of the spectra in (a) and (b). (d) Series of SFG spectra recorded during heating of an ice layer prepared by dosing $20 \mathrm{~L} \mathrm{H}_{2} \mathrm{O}$ at $90 \mathrm{~K}$ to the temperatures indicated in the figure.

$3680 \mathrm{~cm}^{-1}$, which can be attributed to the $\mathrm{p}(3 \times 2)$ overlayer. ${ }^{5 h} \mathrm{~A}$ third resonance, at $3560 \mathrm{~cm}^{-1}$, appears after a $1 \mathrm{~L}$ dose and corresponds to the more dense $\mathrm{c}(4 \times 2)$ overlayer. ${ }^{5 h}$ The three sharp resonances reach saturation after $2 \mathrm{~L} \mathrm{H}_{2} \mathrm{O}$, indicating completion of the monolayer (Fig. 2c). With increasing water coverage $(\geq 3 \mathrm{~L}$ dosage) broad resonances begin to appear below $3500 \mathrm{~cm}^{-1}$ (Fig. 2a and c), which is indicative of hydrogen-bonded $\mathrm{OH}$ within three-dimensional networks of amorphous solid water (ASW). The fact that an SFG signal is obtained from the ASW indicates that a net polarization is built up in this layer, and similar polarization effects have been observed in SFG studies of $\mathrm{CI}$ on $\mathrm{Pt}(111)$ and $\mathrm{Ru}(001){ }^{6}$

The positions and lineshapes of the monolayer related $\mathrm{O}_{\mathrm{s}} \mathrm{H}$ resonances at 3515 and $3560 \mathrm{~cm}^{-1}$ hardly change in the course of the experiment (Fig. 2a), which indicates that the lateral order in the water monolayer is not affected by the thick ASW layer grown on top of it. Spectral modifications do however occur in the region around $3700 \mathrm{~cm}^{-1}$ (Fig. 2b). Specifically, the $\mathrm{OH}_{\mathrm{f}}$ signal from the 1st monolayer (3681-3689 $\mathrm{cm}^{-1}$ ) is gradually replaced by a new peak, which initially appears after exposing the sample to $0.75 \mathrm{~L} \mathrm{H}_{2} \mathrm{O}$ and gradually red-shifts from $3701 \mathrm{~cm}^{-1}$ to $3696 \mathrm{~cm}^{-1}$ by the time the peak saturates $(\sim 5 \mathrm{~L})$. This new signal can be assigned to the presence of dangling $\mathrm{OH}(\mathrm{d}-\mathrm{OH})$ on the surface of the growing ASW layer, ${ }^{5 d}$ and the corresponding disappearance of the $\mathrm{OH}_{\mathrm{f}}$ related resonance results from efficient hydrogen bonding between $\mathrm{OH}_{\mathrm{f}}$ groups in the water monolayer and second layer water molecules. ${ }^{5 h}$

The properties of the interfacial water monolayer during desorption have been studied as well. Fig. $2 \mathrm{~d}$ provides SFG spectra of an $\mathrm{MgO}(001)$ film that was initially covered with $20 \mathrm{~L} \mathrm{H}_{2} \mathrm{O}$ at $90 \mathrm{~K}$ (top spectrum) and then sequentially heated to higher temperatures. After the initial heating step to $140 \mathrm{~K}$, significant broadening of the $\mathrm{O}_{\mathrm{s}} \mathrm{H}$ features, such that both become nearly unresolvable, is noted. The peak broadening is interpreted as an indication of increased disorder in the interfacial layer. This could be caused by enhanced mobility/reorientation in the interfacial layer itself, by increased reorientational dynamics within the $\mathrm{ASW},{ }^{7}$ which could affect the monolayer, or by a combination of the two. The complete disappearance of the ASW features at $150 \mathrm{~K}$ indicates that some combination of ASW-to-CI phase transition and/or multilayer desorption has occurred. Concurrently, the re-emergence of a pronounced, sharp resonance at $3579 \mathrm{~cm}^{-1}(\rightarrow \mathrm{c}(4 \times 2)$ structure $)$, accompanied by a less intense one at $3515 \mathrm{~cm}^{-1}(\rightarrow \mathrm{p}(3 \times 2)$ structure $)$ is noted. While the re-appearance of these peaks clearly indicates the presence of well-ordered monolayer structures, the peak ratio of the signals now shows strong favouritism for the $\mathrm{c}(4 \times 2)$ phase, which suggests that the formation of this more dense structure is kinetically limited at $90 \mathrm{~K}$, where the amplitudes of the two $\mathrm{O}_{\mathrm{s}} \mathrm{H}$ features were similar. As heating the sample is continued from $150-180 \mathrm{~K}$, the gradual loss of the $\mathrm{c}(4 \times 2)$ phase prior to disappearance of the $\mathrm{p}(3 \times 2)$ structure is noted, which is consistent with previous IRAS spectra and reported stabilities for the two monolayer structures. ${ }^{5 b, h} \mathrm{An}$ important piece of information, namely the state of the interfacial water layer during ASW crystallization and the wetting behaviour of CI on $\mathrm{MgO}(001)$, could not be extracted from the SFG data because a spectral distinction between ASW and CI turned out to be outside the scope of direct observation with SFG. Therefore, the ASW $\rightarrow$ CI transition has in more detail been analysed with infrared spectroscopy.

A series of IRA spectra of $\mathrm{D}_{2} \mathrm{O}$ adsorbed on $\mathrm{MgO}(001)$ is shown in Fig. 3a. For $20 \mathrm{~L} \mathrm{D}_{2} \mathrm{O}$ dosed at $90 \mathrm{~K}$, the typical IR spectrum of ASW is obtained (spectrum 1). Heating to $140 \mathrm{~K}$ leads to a slight reduction in overall intensity due to partial water desorption (spectrum 2), and the transition from ASW to CI occurs at $153 \mathrm{~K}$ (spectrum 3). This is followed by the slow desorption of water from the CI state, which was completed after holding the temperature at $153 \mathrm{~K}$ for $\sim 500 \mathrm{~s}$ (spectrum 8).

To gain insight into the changes of the monolayer OD signals during the ASW $\rightarrow$ CI transition and subsequent desorption, the 


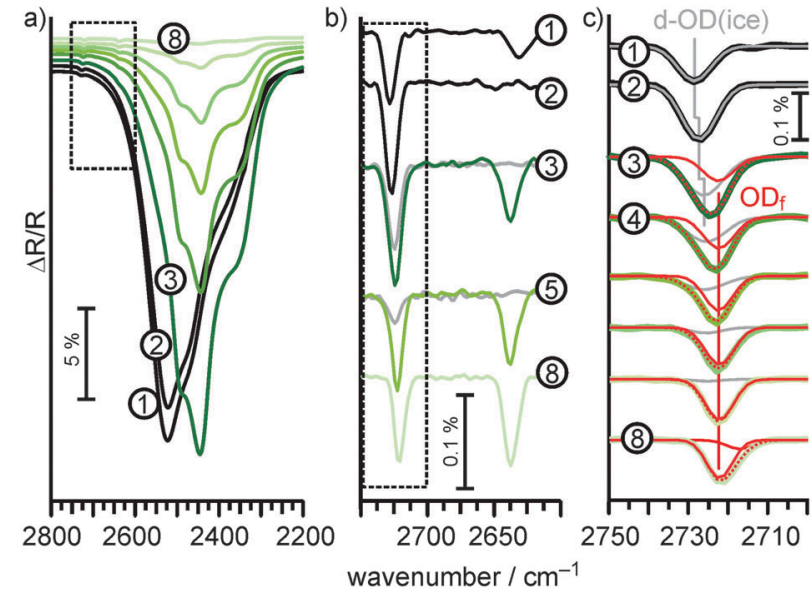

Fig. 3 Results of IRAS experiments for $20 \mathrm{LD}_{2} \mathrm{O}$ dosed at $90 \mathrm{~K}$ on $20 \mathrm{ML} \mathrm{MgO(001)/}$ $\mathrm{Ag}(001)$ (spectrum 1), after heating to $140 \mathrm{~K}$ (spectrum 2), crystallization at $153 \mathrm{~K}$ (spectrum 3), and subsequent desorption of crystalline ice at $153 \mathrm{~K}$ (spectra 4-8). (a) Full OD range; (b) $2600-2750 \mathrm{~cm}^{-1}$ region after subtraction of the broad bulk ice features (the grey traces added to spectra 3 and 5 were obtained from the corresponding states of ice on $\mathrm{Ag}(001)$ ); (c) details of the spectral region around $2725 \mathrm{~cm}^{-1}$ and results of fits for the $\mathrm{d}-\mathrm{OD}$, grey, and $\mathrm{OD}_{\mathrm{f}}$, red, contributions.

broad features associated with multilayer ice have been subtracted from the spectra. The spectral region of interest $\left(2750-2600 \mathrm{~cm}^{-1}\right)$ is displayed in Fig. 3b. A small but relatively narrow band at $2630 \mathrm{~cm}^{-1}$ ( $3560 \mathrm{~cm}^{-1}$ in the $\mathrm{OH}$ region) is present in spectrum 1 , corresponding to $\mathrm{O}_{\mathrm{s}} \mathrm{D}$ in the $\mathrm{c}(4 \times 2)$ structure. The $\mathrm{O}_{\mathrm{s}} \mathrm{D}$ signal from the $\mathrm{p}(3 \times 2)$ overlayer would appear at $2593 \mathrm{~cm}^{-1},{ }^{5 h}$ but, due to its small absorption, this signal could not be extracted from the spectra. Upon heating to $140 \mathrm{~K}$ (spectrum 2), detection of the $\mathrm{O}_{\mathrm{S}} \mathrm{D}$ signal is lost, and the only narrow band observed in IRAS is the d-OD signal at $2730 \mathrm{~cm}^{-1}$. However, after additionally heating to the ASW $\rightarrow$ CI transition at $153 \mathrm{~K}$ (spectrum 3), the $\mathrm{O}_{\mathrm{s}} \mathrm{D}$ band reappears and continues to grow as the multilayer desorbs.

To further probe the changes occurring during crystallization and CI desorption, the spectral region around $2725 \mathrm{~cm}^{-1}$ has been analyzed in more detail using spectral fitting (Fig. 3c). To aid in the deconvolution of the signals into their individual d-OD and $\mathrm{OD}_{\mathrm{f}}$ components, the fate of d-OD during the desorption of CI grown on $\mathrm{Ag}(001)$, which is free of monolayer-related features, ${ }^{8}$ has been probed separately (grey traces in spectra 3 and 5 in Fig. 3b). In spectra 1 and 2 in Fig. 3c, which were taken from ASW at $90 \mathrm{~K}$ and $140 \mathrm{~K}$, the band is symmetric and can be fit with a single component corresponding to d-OD. Upon crystallization (spectrum 3), the band red-shifts and becomes asymmetric with a tail extending towards higher frequencies. At this point, two components are necessary to properly fit the band, with the higher frequency one corresponding to d-OD from the ice surface, and the lower frequency one $\left(2722 \mathrm{~cm}^{-1}\right)$ assigned to $\mathrm{OD}_{\mathrm{f}}$ from the water monolayer on $\mathrm{MgO}(001)$. As the d-OD signal gradually disappears during subsequent desorption of CI, the intensity of the $\mathrm{OD}_{\mathrm{f}}$ feature increases until multilayer desorption is complete and only the ordered water monolayer remains (spectrum 8). The results in Fig. $3 \mathrm{c}$ show that the appearance of the $\mathrm{OD}_{\mathrm{f}}$ feature from the water monolayer on $\mathrm{MgO}$ occurs with the transition from ASW to CI and well in advance of complete multilayer desorption. This indicates dewetting of the multilayer ice upon transition to CI, such that portions of the monolayer become exposed to vacuum.
These results can be set into the context of findings from previous studies conducted on transition-metal surfaces. Hodgson and Haq suggest that there is a strong dependence between the wetting behaviour of CI on metals and the ability to form $\mathrm{H}$-bonds between mono- and multilayer as well as the flexibility of the interfacial water structures needed to stabilize the ordered ice phase. ${ }^{3}$ Despite the presence of H-bond interactions with the ASW phase in the case of the interfacial water monolayer on $\mathrm{MgO}$, the strong bonding between the unfavourably commensurate rectangular monolayer structure and the $\mathrm{MgO}(001)$ surface does not favour relaxation into a structure capable of stabilizing the bulk CI-oxide interface. As a consequence, and in agreement with arguments established for ice-metal interfaces, crystalline ice does not wet the $\mathrm{MgO}(001)$ surface.

In summary, a detailed picture of the properties of ice on $\mathrm{MgO}(001)$ has been obtained using vibrational spectroscopy. The results show that stable monolayer structures of both $\mathrm{p}(3 \times 2)$ and $c(4 \times 2)$ symmetry are formed in the initial stages of growth and that the lateral order of the monolayer is not affected by further adsorption of water, while there is significant interaction between first and second layer water molecules via hydrogen bonding. When heating to the ASW $\rightarrow$ CI transition, the monolayer relaxes to favour the more dense $\mathrm{c}(4 \times 2)$ structure. At the same time, $\mathrm{OH}_{\mathrm{f}}$ groups of the monolayer water appear, which provides spectroscopic evidence for ice dewetting upon crystallization.

We thank William E. Kaden for critically reading the manuscript and Hans-Joachim Freund for his continued support. Y.F. acknowledges financial support from Co. Ltd. Takata and DAAD.

\section{Notes and references}

1 (a) P. A. Thiel and T. E. Madey, Surf. Sci. Rep., 1987, 7, 211; (b) M. A. Henderson, Surf. Sci. Rep., 2002, 46, 1; (c) G. E. Brown, V. E. Henrich, W. H. Casey, D. L. Clark, C. Eggleston, A. Felmy, D. W. Goodman, M. Grätzel, G. Maciel, M. I. McCarthy, K. H. Nealson, D. A. Sverjensky, M. F. Toney and J. M. Zachara, Chem. Rev., 1999, 99, 77; (d) A. Verdaguer, G. M. Sacha, H. Bluhm and M. Salmeron, Chem. Rev., 2006, 106, 1478; (e) G. E. Ewing, Chem. Rev., 2006, 106, 1511.

2 (a) G. A. Kimmel, N. G. Petrik, Z. Dohnalek and B. D. Kay, Phys. Rev. Lett., 2005, 95, 166102; (b) K. Thürmer and N. C. Bartelt, Phys. Rev. Lett., 2008, 100, 186101; (c) M. E. Gallagher, S. Haq, A. Omer and A. Hodgson, Surf. Sci., 2007, 601, 268; (d) G. Zimbitas, M. E. Gallagher, G. R. Darling and A. Hodgson, J. Chem. Phys., 2008, 128, 074701.

3 A. Hodgson and S. Haq, Surf. Sci. Rep., 2009, 64, 381.

4 (a) S. Yamamoto, A. Beniya, K. Mukai, Y. Yamashita and J. Yoshinobu, J. Phys. Chem. B, 2005, 109, 5816; (b) A. Beniya, Y. Sakaguchi, T. Narushima, K. Mukai, Y. Yamashita, S. Yoshimoto and J. Yoshinobu, J. Chem. Phys., 2009, 130, 034706.

5 (a) J. Heidberg, B. Redlich and D. Wetter, Ber. Bunsen-Ges. Phys. Chem., 1995, 99, 1333; (b) D. Ferry, A. Glebov, V. Senz, J. Suzanne, J. P. Toennies and H. Weiss, J. Chem. Phys., 1996, 105, 1697; (c) M. J. Stirniman, C. Huang, R. S. Smith, S. A. Joyce and B. D. Kay, J. Chem. Phys., 1996, 105, 1295; (d) C. Xu and D. W. Goodman, Chem. Phys. Lett., 1997, 265, 341; (e) L. Giordano, J. Goniakowski and J. Suzanne, Phys. Rev. Lett., 1998, 81, 1271; $(f)$ B. Demirdjian, J. Suzanne, D. Ferry, J. P. Coulomb and L. Giordano, Surf. Sci., 2000, 46, L581; $(g)$ Y. D. Kim, R. M. Lynden-Bell, A. Alavi, J. Stulz and D. W. Goodman, Chem. Phys. Lett., 2002, 352, 318; (h) R. Wlodarczyk, M. Sierka, K. Kwapien, J. Sauer, E. Carrasco, A. Aumer, J. F. Gomes, M. Sterrer and H.-J. Freund, J. Phys. Chem. C, 2011, 115, 6764.

6 (a) X. C. Su, L. Lianos, Y. R. Shen and G. A. Somorjai, Phys. Rev. Lett., 1998, 80, 1533; (b) J. Kubota, A. Wada, K. Domen and S. S. Kano, Chem. Phys. Lett., 2002, 362, 476; (c) D. N. Denzler, C. Hess, R. Dudek, S. Wagner, C. Frischkorn, M. Wolf and G. Ertl, Chem. Phys. Lett., 2003, 376, 618.

7 (a) G. P. Johari, A. Hallbrucker and E. Mayer, J. Chem. Phys., 1991, 95, 2955;

(b) M. J. Jedema, M. J. Dresser, D. L. Doering, J. B. Rowland, W. P. Hess,

A. A. Tsekouras and J. P. Cowin, J. Phys. Chem. B, 1998, 102, 9203.

8 M. Klaua and T. E. Madey, Surf. Sci., 1984, 136, L42. 